\title{
Identification of common points in hybrid geodetic networks to determine vertical movements of the Earth's crust
}

https://doi.org/10.1515/jag-2021-0002

Received January 11, 2021; accepted February 23, 2021

\begin{abstract}
Simultaneous use of data repeated levelling measurements and continuous GNSS observations allows increasing the spatial resolution of geodynamics models. For this purpose, it is necessary to create a single network, a so-called hybrid network.

This paper aims at examining the possibility of using scale-free network theory to determine the most relevant common points in hybrid networks using the distance criterion. Used on European network points: UELN (United European Levelling Network) and EPN (European Permanent GPS Network) and the regional network.

In the hybrid network (UELN + EPN), 18 pseudo-nodal points with the highest number of links were identified. The accepted distance criterion shows that about $90 \%$ of the EPN points can be used as common points. The application of the scale-free network theory allows determining the significance of points in a hybrid network.
\end{abstract}

Keywords: hybrid networks, pseudo nodal point, vertical crustal movements, scale-free network

\section{Introduction}

Among others, geodetic data is used to analyse changes in the Earth's shape, to analyse changes in the surface of the Earth's crust [51, 27, 24, 11, 32] and to maintain and modify Earth's reference systems [23, 49, 45]. In this research, it is crucial to identify changes over time. This data includes the results of geodetic ground and satellite measurements $[28,8,31]$. Satellite systems include GNSS - Global Navigation Satellite Systems [50], VLBI - Very-long-baseline in-

\footnotetext{
*Corresponding author: Kamil Kowalczyk, University of Warmia and Mazury in Olsztyn, Institute of Geodesy and Civil Engineering, Oczapowskiego 2, 10-719 Olsztyn, Poland, e-mail:

kamil.kowalczyk@uwm.edu.pl, ORCID:

https://orcid.org/0000-0001-7428-6097

Anna Maria Kowalczyk, Jacek Rapiński, University of Warmia and Mazury in Olsztyn, Institute of Geodesy and Civil Engineering, Oczapowskiego 2, 10-719 Olsztyn, Poland, e-mails: anna.kowalczyk@uwm.edu.pl, jacek.rapinski@uwm.edu.pl
}

terferometry [43], SLR - Satellite laser ranging [2], InSAR Interferometric synthetic aperture radar [41]. Ground measurements include, among others: ALS - Airborne Laser Scanning [13], linear and angular measurements [40] and levelling [15].

The multitude of measurement systems makes it possible to inter-verify the results obtained and, at the same time, to use sets from different sources, e. g. the European Ground Motion Service (EU-GMS) project. Research and implementation of projects based on combining data sets obtained with different techniques (e.g. European Vertical Reference Network [EUVN]) exhibit practical and methodological problems with combining different geodetic observation techniques, especially geometric data related to space and gravity field [23].

Due to the different spatial resolution of the sets and their interconnection, to use them all simultaneously it is necessary to apply interpolation techniques $[20,44,22,53$, $16,38]$ or statistical and mathematical techniques [52, 33]. There are also works presenting the same phenomenon using different measurement techniques on separate maps without any attempt to combine them. [30, 39, 6, 18, 46, 17]. Interpolation methods do well in combining sets with unknown mutual relations between them or when it is determined by additional analyses, e. g. set anisotropy, variants analysis, nugget effects, etc. [14]. When using statistical and mathematical methods based on the simultaneous alignment of several networks (e.g. a triple-levelling network, hybrid network), the spatial distribution of adjustment points, identification of common points, attribution of weights to common and adjustment points and observations between network points are crucial.

In large geodetic networks, there are only a few or a dozen or so significant main points. In the UELN European levelling network, 13 points out of approximately 8,000 were selected as major when implementing the EVRF2007 European coordinate system. During the implementation of EVRF2019, 12 such points were adopted. The literature lacks guidelines on the spatial distribution of adjustment points, their maximum number, especially when it comes to the alignment of networks of relative vertical movements of the Earth's crust. The spatial distribution may be 
consistent with the assumptions used in the transformation between coordinate systems [19, 25]:

- they should be evenly distributed over the area (and its surroundings) covered by the transformation, both inside and outside,

- the set of adjustment points must include such a subset that; when connected in a closed sequence, it forms a figure containing all the transformed points

- satisfy the inequality:

$$
n=n_{1}+\frac{n_{2}}{2} \geq 4
$$

where, $n_{1}$ indicates the number of class adjustment points with a factor $<k-1$ and $n_{2}$ is the number of class adjustment points $k-1$. (The basic condition is that these are higher-order matrix points refer to a physically identical geodetic sign), $k$ - is the agreed accuracy class indicator of transformed points e. g. $k=$ $1,2,3,4$ ( $k=1$ - highest accuracy class).

The spatial distribution may also be determined through other, well-documented criteria, such as tectonic and geological location, point class, number of links [47], observations from different measurement techniques, meteorological parameters, surrounding information of the stations, e. g. eccentricities and groundwater level [23, 45], network structures $[4,37,1]$ and the operation time of a permanent station [27]. To determine the significance of a point in the network, its spatial links with other points in the network can be used - network analyses. The number of links can be determined directly [47] or using scale-free network theory $[3,5,12,35]$. This theory analyses the network layout to select the major node network points $[42,29,36]$.

In addition to adjustment points (which do not have to simultaneously belong to several aligned networks), it is important to identify common points if networks measured by different techniques, at different points or at different times, are aligned. Among others, this related to the determination of vertical movements of the Earth's crust using different types of data. Such a case is presented in Figure 1, where double levelling lines, an artificially created network of vertical movements between GNSS stations, and gravimetric lines are shown. Based on each of these networks, it is possible to determine the relative vertical movements of the Earth's crust. To determine the common vertical movements of the Earth's crust (simultaneous alignment of three networks - a hybrid network), it is necessary to identify the so-called pseudo nodal points.

It is not always possible to use different techniques for measurements over the same physically stabilised point of the geodetic or gravimetric matrix or measurement data is

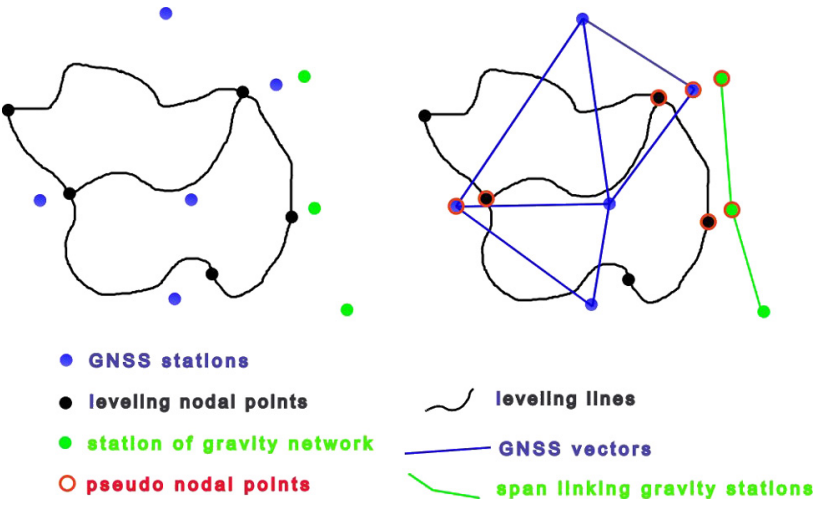

Figure 1: Example of creating a hybrid network: lines and benchmarks of a double levelling network, lines, and points of a gravimetric network, stations and links to GNSS stations.

missing. In this case, it should be assumed that two (or more) measurement points, at a certain distance from each other (distance criterion), constitute one point (a pseudonodal point) - Figure 2.

The distance criterion is determined based on the adopted measuring technique and the point distribution density. As [23] states, when combining networks based on varied measuring techniques, the distances between individual measuring points should be sufficiently small. However, he does not specify a distance criterion. In article [7] showed that points that are $10 \mathrm{~km}$ apart show no significant altitude changes over time. This distance can be up to $40 \mathrm{~km}$ [21].

In double and triple levelling networks (a network of vertical movements based on precision levelling data), an observation is understood as unbalanced vertical movement between points in these networks. If the points cannot be found simultaneously in these three networks, they may be linked through other points of the double or triple levelling network [14]. If there are no direct, typical observations (links) between the points at all, as is the case with permanent GNSS stations [26], and the vertical movements of the Earth's crust are determined pointwise [10], the indirect method can be used for this purpose - e. g. Delaunay triangulation [34].

Regardless of the shape of the network, the number of points, geological location, etc., the selection of the common points between the used networks is crucial at the hybrid network alignment stage. This paper aims at examining the possibility of using the scale-free network theory to determine the most relevant common points in hybrid networks using the distance criterion. 
a)

c)

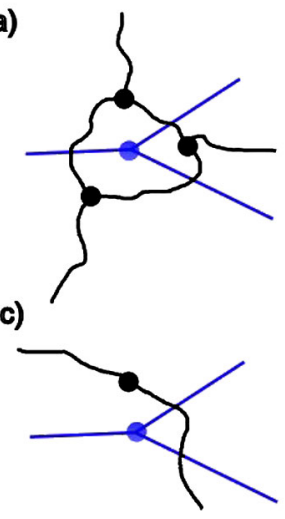

- GNSS statlons

- levellng nodal polnts b)

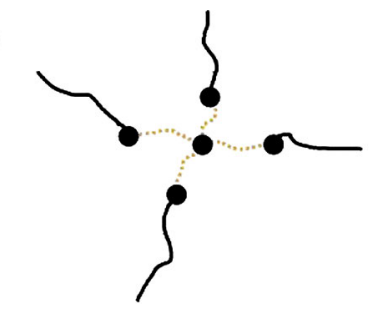

d)
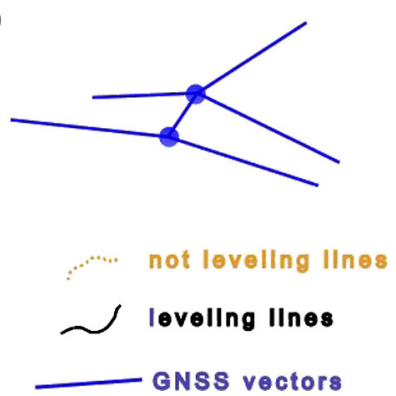

Figure 2: Instances of pseudo-nodal points: a) double levelling network points around a GNSS station, b) benchmarks around a double levelling node point for which no elevation data is available, c) individual benchmarks around a double levelling network near a GNSS station, d) GNSS stations in the vicinity.

\section{Data used}

The study uses points and junctions into the UELN (United European Levelling Network) and EPN (European Permanent Network) networks.

The United European Levelling Network (UELN) is based on the precision levelling network of individual European countries and serves as a basis of the European Vertical Reference System (EVRF2007). Since measurements of these networks were performed cyclically in different measurement epochs, the UELN can be treated as a double, triple and sometimes quadruple levelling network. 13 points out of the proposed 20 were adopted as major in UELN (Figure 3a). The basic rejection criteria included a significant change in altitude over time and a small number of points common with other networks. The network consists of 8,133 nodal points (which are used as a basis for the alignment of national networks), 13 major points, and 10,568 links between points [48]. The links were identified based on materials downloaded from https://evrs. bkg.bund.de and the .shp file made available by prof. M. Sacher.

European Permanent GPS Network (EPN) is a network of permanent GNSS tracking stations to realise the European Terrestrial Reference System (ETRS) [9]. More than 350 EPN stations are distributed all over Europe (Figure $3 \mathrm{~b})$. The GNSS data from the EPN stations are freely available through the internet https://www.epncb.oma.

be. Links between points of the EPN were determined using Delaunay triangulation.

\section{Identification of common points in EULN and EPN}

To create a hybrid geodetic network, two (or more) geodetic networks (measured by different techniques) must be joined through so-called common points. If the measurement is made on the same, physically stabilised field points, these may become nodal points. If such points are missing, they can be identified as pseudo-nodal points. There are many criteria for identification. From the point of view of spatial (statistical and mathematical) analysis, the distance criterion is the most appropriate. When using this criterion, we need to determine the maximum or optimum distance between two points from different surveying which will be treated as a single point (pseudo-nodal points) later in the process of aligning the hybrid network (Figure 2). Such a solution works well for determining vertical movements of the Earth's crust because the latter does not change point-wise but in a certain area. The distance criterion was applied to identify common points in UELN and the GNSS fixed station network - EPN. Pseudonodal points in a pre-set of six constant distances were then identified (Figure 4).

In [7] showed that in a dual levelling network, points lying at a distance of up to $10 \mathrm{~km}$ from a nodal point exhibit vertical traffic movement $0.0 \mathrm{~mm} / \mathrm{yr}$ and $0.25 \mathrm{~mm} / \mathrm{yr}$. The dependence is not linear. For the assumed optimal distance $(10 \mathrm{~km})$, almost $90 \%$ of EPN points have their neighbour in the UELN network. For further spatial analyses, we assumed that this criterion is fundamental.

\section{Assessment of the significance of nodal points and pseudo-nodal points in a network}

\subsection{Network analysis - theory}

In network-modelled spatial structures, there are two types of networks to be distinguished: random networks and scale-free networks. Nodes in random networks have approximately the same number of links (Figure 5a). The distribution in such a network is represented by the characteristic Poisson distribution curve. 
a)

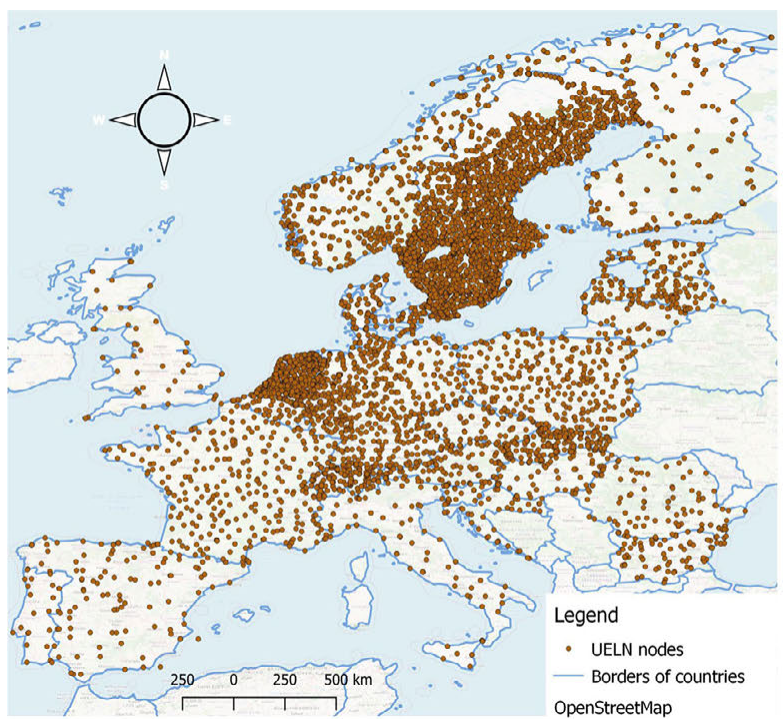

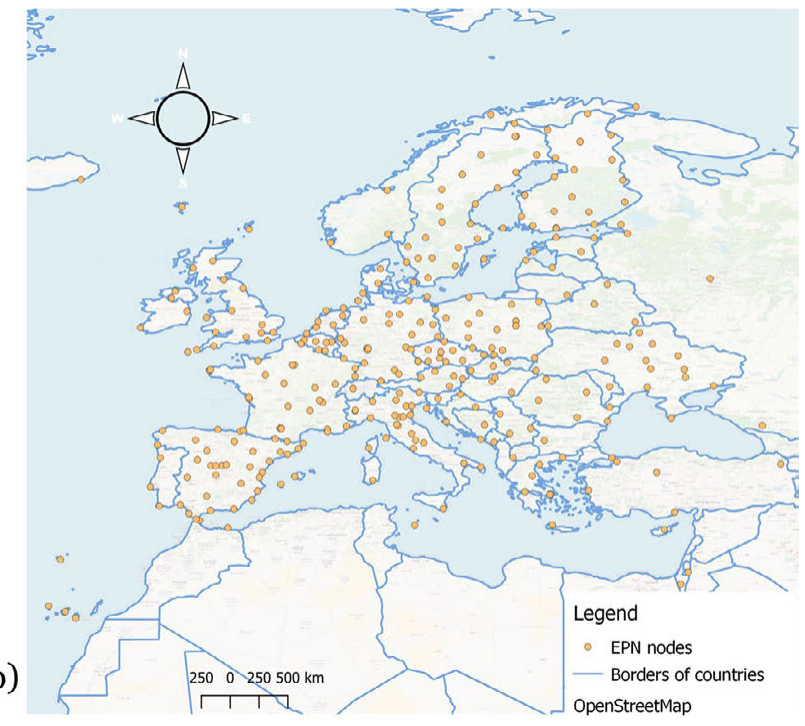

Figure 3: a) points of the United European Levelling Network (UELN), b) points of a permanent station in EPN https://evrs.bkg.bund.de; https://www.epncb.oma.be.

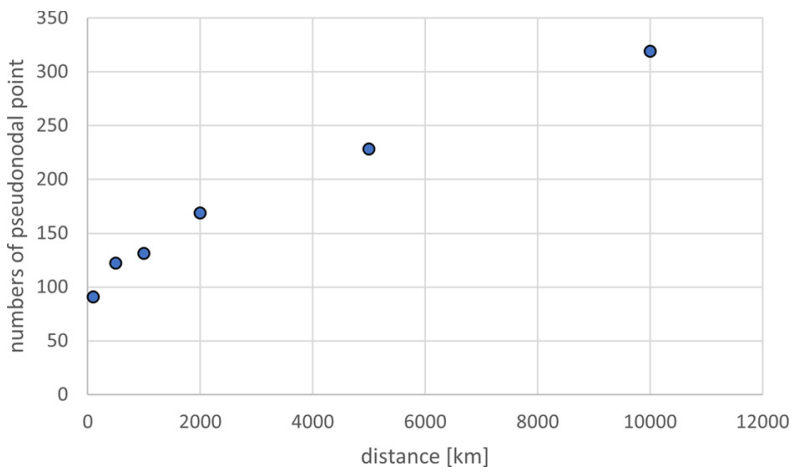

Figure 4: Identification pseudo nodal points in UELN and EPN networks.

In scale-free networks, the distribution of the number of links and the number of nodes with a specific number of links is different from that of random networks.

Nodes which have many more links than others are identified. These nodes are called hubs. In contrast to random networks, preferential selection of links occurs here, which means that newly created nodes are the most willing to connect with the hubs. The distribution of this network is represented by the power function (Figure $5 b$ ).

If a given network is identified as scale-free, this means hubs can be identified in such a network. These hubs are strategic and important for the whole network. Figures 6 and 7 illustrate situations in which:

a) random nodes are excluded from operation (destroyed) in a scale-free network, b) a pre-defined hub is excluded from operation (destroyed) in a scale-free network.

This is not the case with random networks. Here, due to the fact that there are no hubs, no strategic points, the dysfunctionality of such a network may arise from the random destruction of a large number of nodes.

\subsection{Identification of significant nodes in the EPN network}

The EPN network consists of 343 points. Links are generated by Delaunay triangulation (Figure 8). The analysis shows that most of the nodes have a similar number of links, although some nodes with an above-average number of links can be identified.

The average number of links is 4 to 8 ( 332 nodes), several nodes have from 9 to 12 links (11 nodes), which makes them unique (strong nodes) in the entire network structure. Such a number of links is extremely rare. This may be indicative of the scale-free character of the analysed network (Figure 9).

After analysis and verification of the results, it was established that a point with 12 links should be removed from the list of strong nodes (those with a large number of links). Its large number of links does not result from its "weight" but its borderline position. This position has forced the triangulation analysis tool to create links to this point, thus increasing the total number of links. The final arrangement of the nodes is shown in Figure 10. 
a)

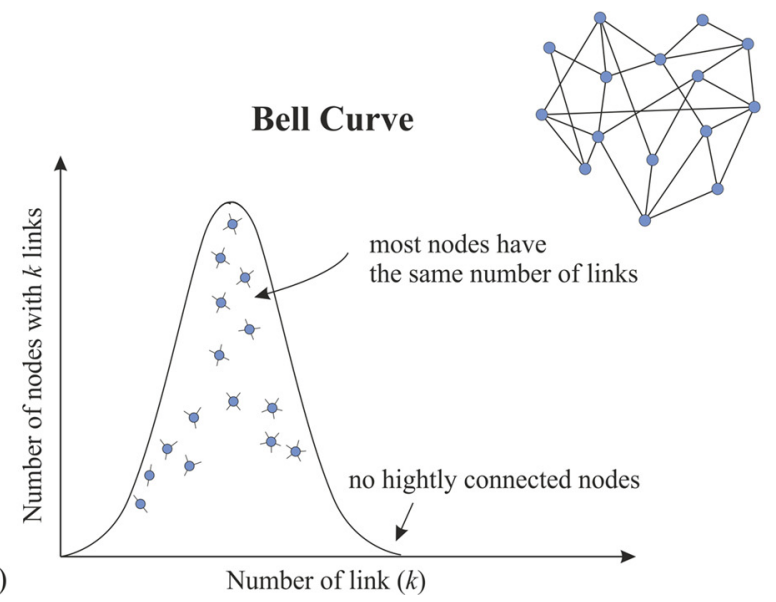

b)

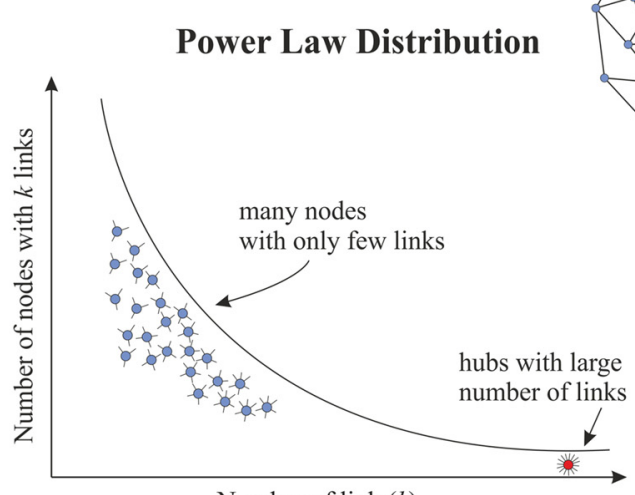

Figure 5: a) Random network - normal distribution, b) Scale-free network - power law distribution. Source: [7, 36].
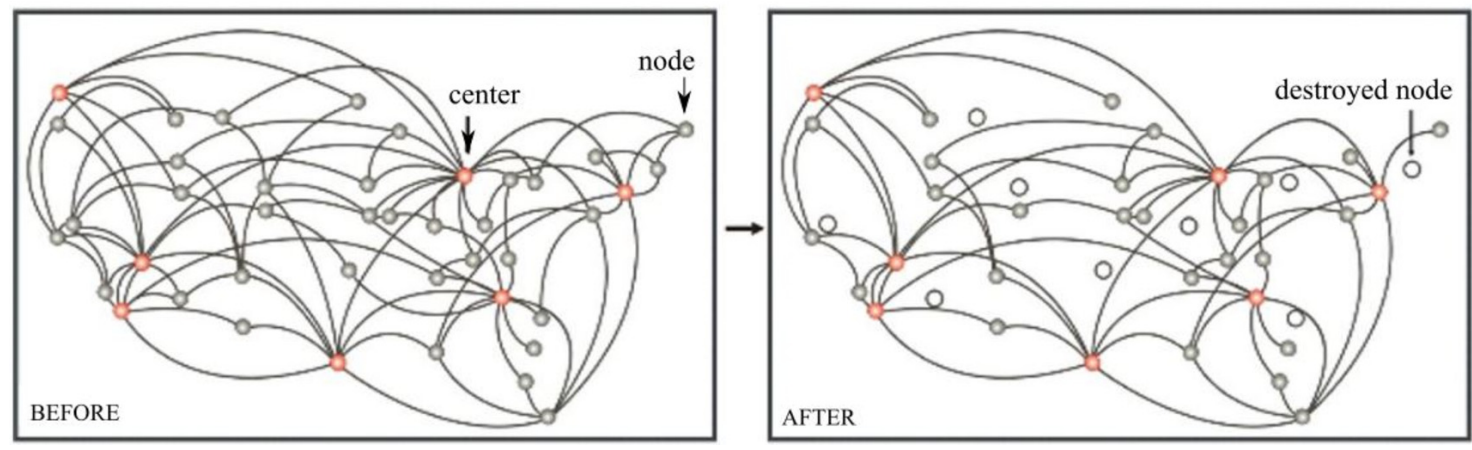

Figure 6: Scale-free network - random attack on the nodes. Source: [7, 36, 3].
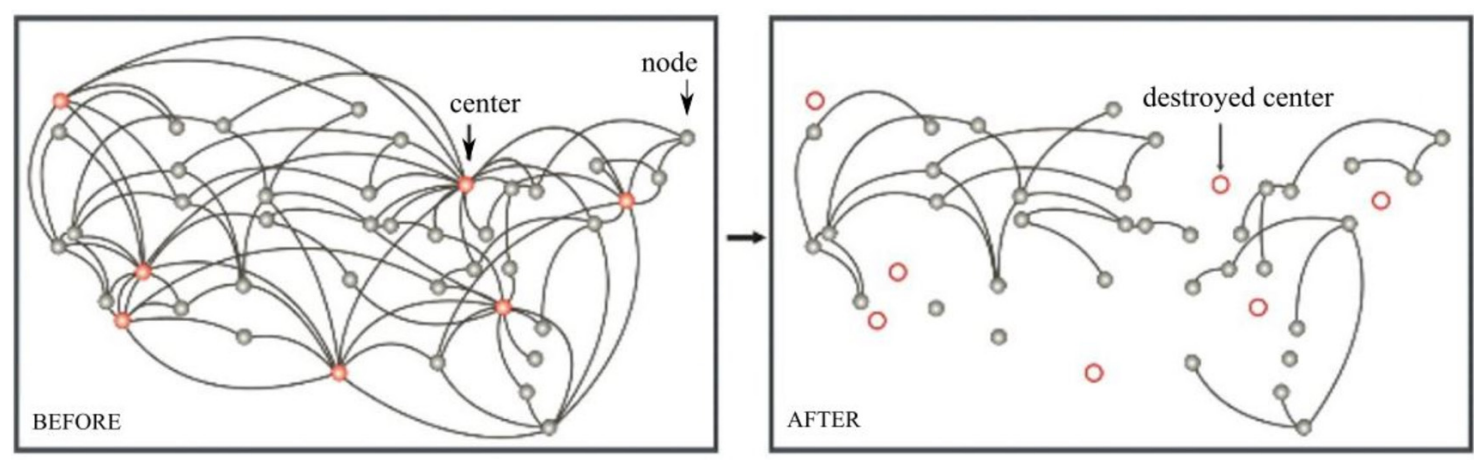

Figure 7: Scale-free network - intentional attack on the centres. Source: [7, 36, 3].

\subsection{Identification of significant nodes in the UELN network}

In the analysed structure, the ULEN network has 6,302 nodes. From the analysis of links (Figure 11) between the nodes, it results that most nodes have two (1,832 nodes) or three (3,164 nodes) links. In this structure, similar to the EPN network analysed above, some individual strong nodes were identified with a large number of links in relation to the remaining points in the set.

The average number of links ranges from one to five (3,299 nodes), two nodes have 6 links and one has 8 (Figure 12). With reference to the theory of scale-free networks, these three nodes (Figure 13) can be considered strong nodes (hubs). 


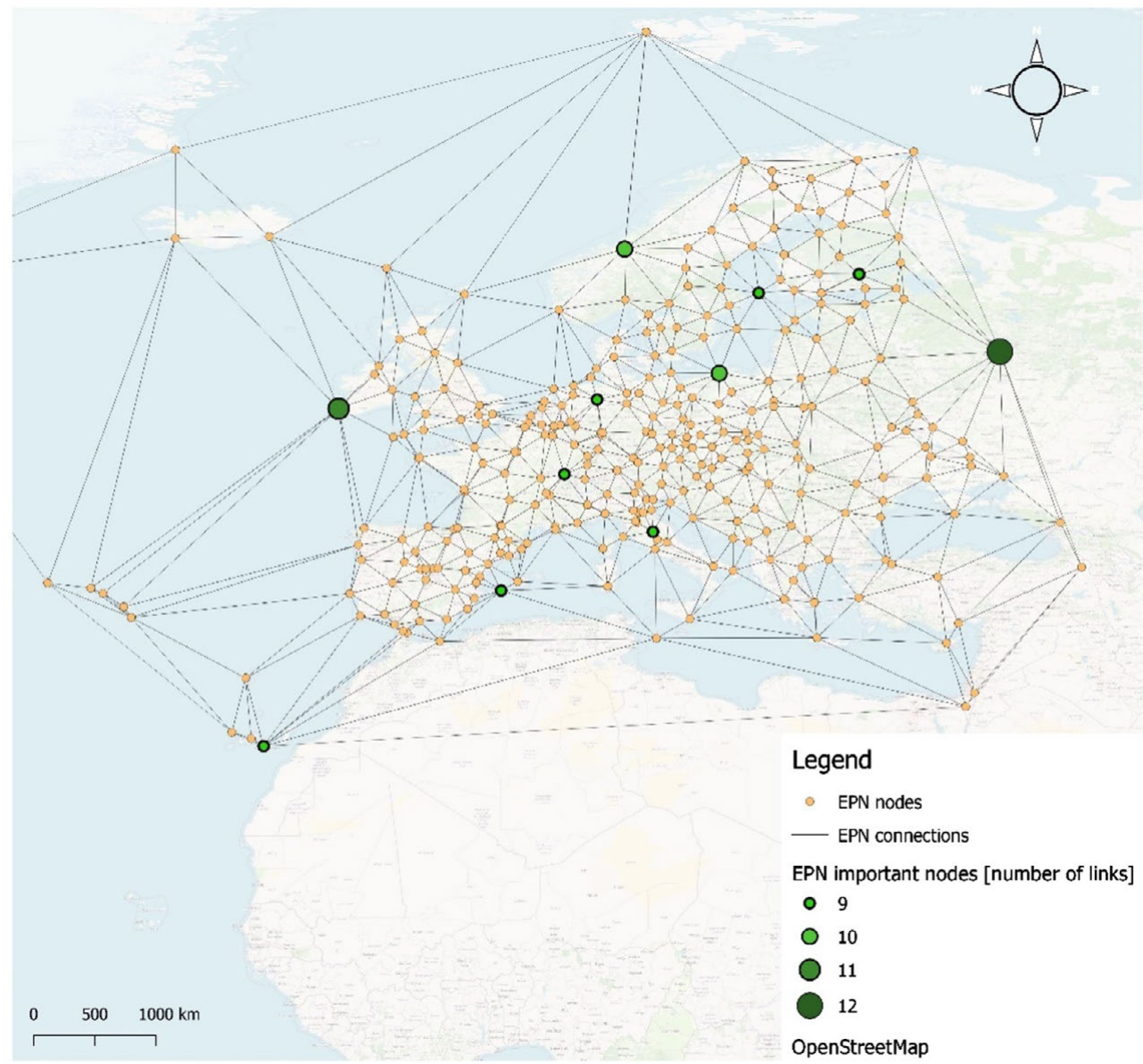

Figure 8: Significant nodal points in the EPN.

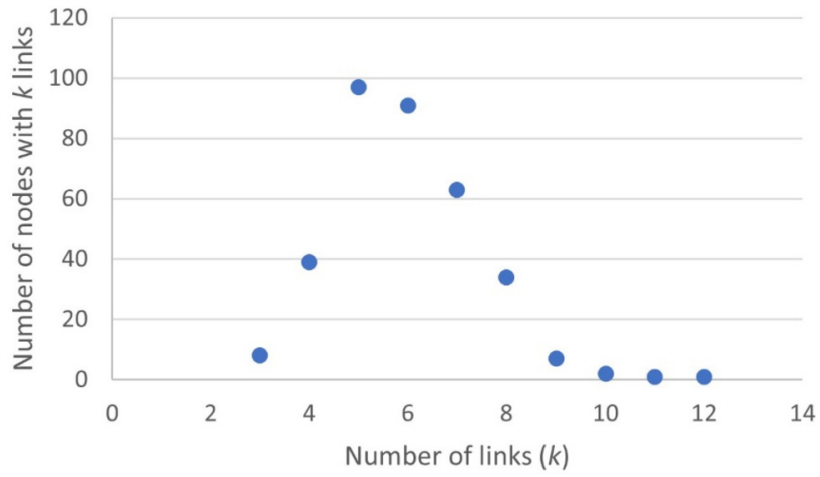

Figure 9: EPN - The EUREF Permanent GNSS Network. The analysis of its structure - nodes with a specified number of connections. Source: own analysis.

\subsection{Identification of significant pseudo-nodal points in a hybrid network}

For this analysis, it was assumed that both networks (UELN and EPN) were joined into a single hybrid network based on the identification of common points at assumed distances. It was determined how the network structure is shaped, assuming that the points at a respective distance of 10,000, 5,000, 2,000, 1,000 and 500 meters constitute the same node. The results are presented in Table 1.

For further analysis and identification of the nodes with the largest number of links, which are thus the most important in the network structure, a distance of 10,000 metres was assumed. In such a hybrid network, 18 strong nodes were identified, thirteen of them have 11 links, four have 12 links and one has 13 (Figure 14). The identified pseudo-nodal points account for $90 \%$ of the EPN network points.

The distribution of nodes and links presented below (Figure 15) shows that most nodes have approximately the same number of links and nodes with more than 10 links are rare. Based on the analysis, they can be assumed to be the most important in the network structure.

The nodes identified as most important in the hybrid network were subjected to verification with the results of other researchers (Figure 16). 


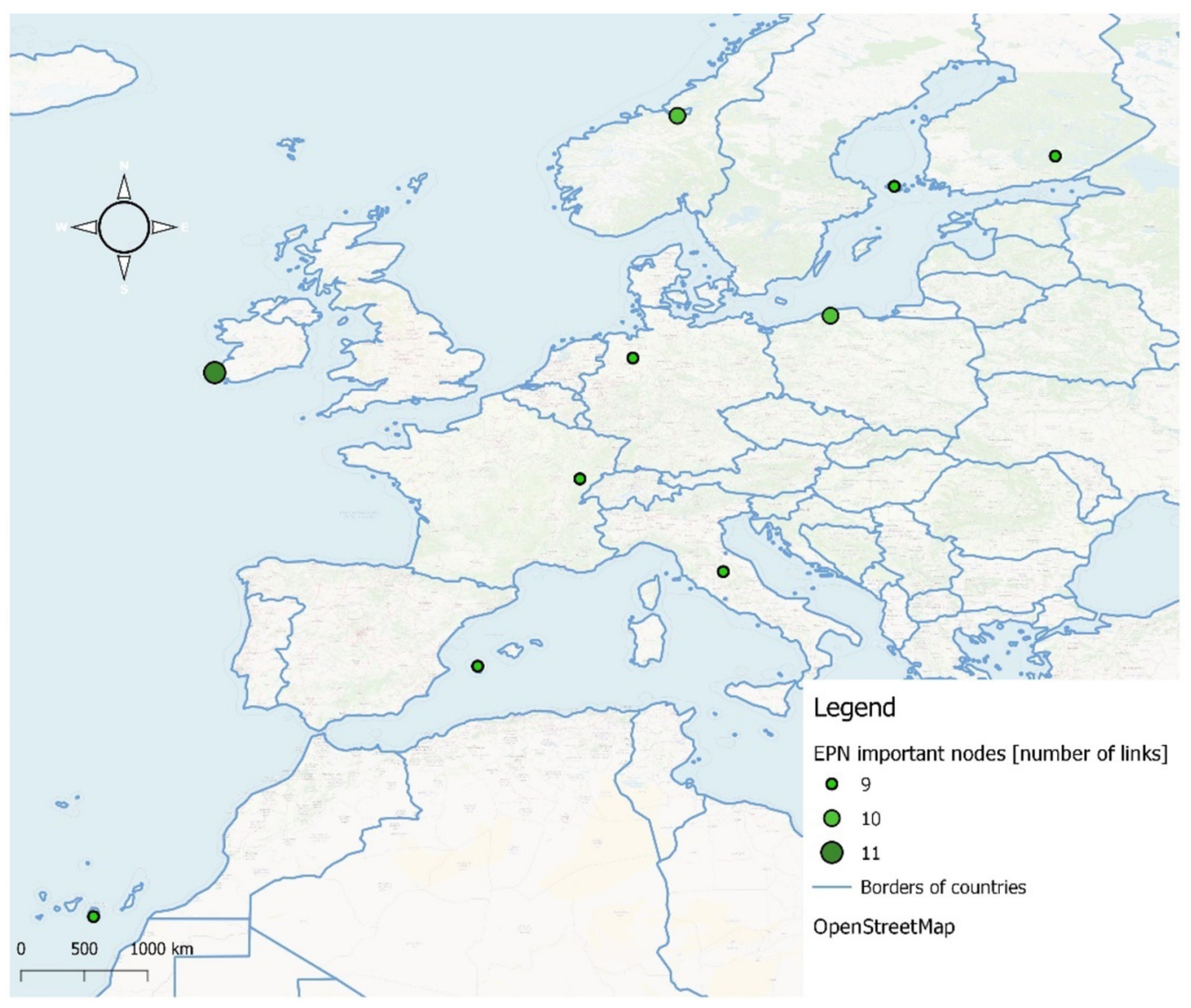

Figure 10: EPN - The EUREF Permanent GNSS Network. The nodes with the highest number of connections. Source: own analysis.

Table 1: Common points in EPN and UELN networks depending on the distance criterion.

\begin{tabular}{rrrrrrr}
\hline Number of links & \multicolumn{7}{l}{ Distances [m] } \\
\cline { 2 - 7 } & $\mathbf{1 0 0 0 0}$ & $\mathbf{5 0 0 0}$ & $\mathbf{2 0 0 0}$ & $\mathbf{1 0 0 0}$ & $\mathbf{5 0 0}$ & $\mathbf{1 0 0}$ \\
\hline 5 & 17 & 14 & 12 & 12 & 11 & 6 \\
6 & 22 & 21 & 16 & 14 & 13 & 10 \\
7 & 42 & 29 & 23 & 19 & 17 & 12 \\
8 & 54 & 33 & 26 & 17 & 15 & 8 \\
9 & 41 & 26 & 14 & 10 & 8 & 4 \\
10 & 19 & 10 & 5 & 2 & 1 & 1 \\
11 & 13 & 6 & 2 & 1 & 1 & 1 \\
12 & 4 & 2 & - & - & - & - \\
13 & 1 & - & - & - & - & - \\
\hline
\end{tabular}

\section{Testing the method - case study}

Data from Poland were used for testing. Four precision levelling measurement campaigns have been conducted in Poland so far. The two more recent ones mostly covered the same points in the national altitude network. They were included in successive versions of UELN. Based on these two campaigns, a double levelling network was created (Figure 17a) and a model of relative vertical movements in Poland was developed. Observations included unbalanced vertical movements between nodal points of the double levelling network.

In Poland, there is a network of permanent GNSS stations being part of EUPOS, although selected stations belong to the EPN network. In 2017, relative vertical movements between these stations were identified and the network of vertical movements created in this way was subjected to initial alignment [34]. Observations included unbalanced vertical movements between GNSS stations of the ASG EUPOS network. The links between the stations were determined using Delaunay triangulation (Figure 17b).

GNSS stations of the Polish ASG-EUPOS system do not physically overlap with nodal points of the basic altitude matrix. In order to develop a relative model of vertical movements of the Earth's crust in Poland based on levelling data and GNSS station data, both networks must be aligned simultaneously. For this purpose, both networks were treated as a hybrid network. Common points were 


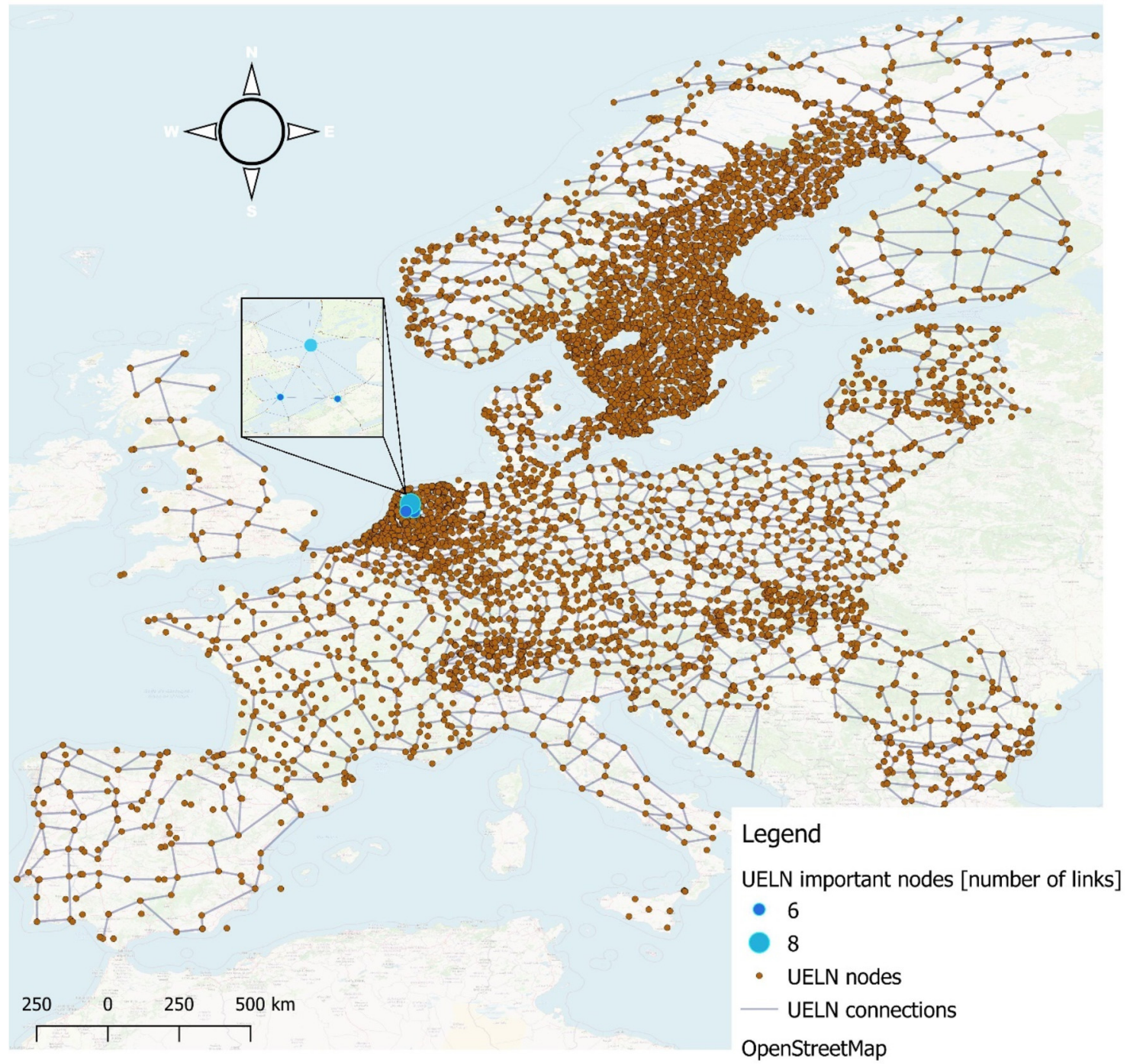

Figure 11: UELN - The United European Levelling Network. Source: own analysis.

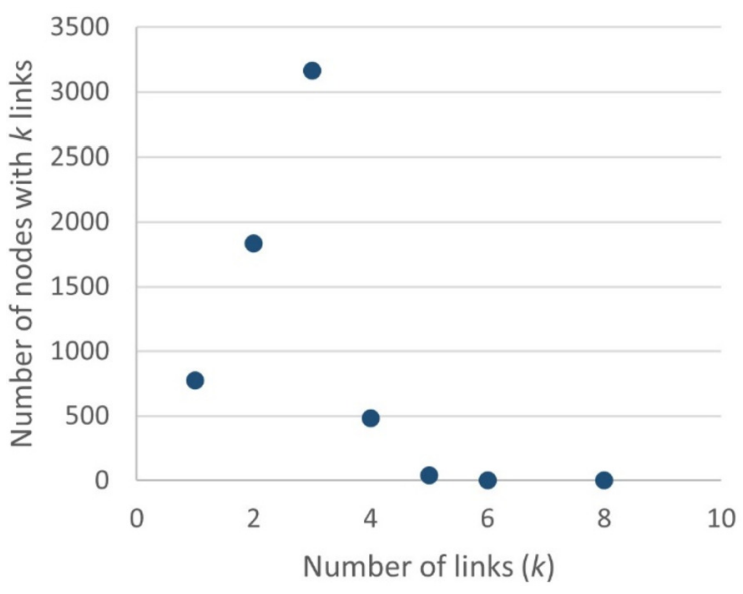

Figure 12: UELN - The United European Levelling Network. The analysis of its structure - nodes with a specified number of connections. Source: own analysis. also identified according to the previously described assumptions.

\subsection{Identification of common points in the vertical movements' network}

Analyses similar to the European networks have been carried out for the territory of Poland using the data described above. The double levelling network included 234 nodes and 781 links, while the network of links between points of the Polish ASG EUPOS network included 124 points and 692 links, respectively. In the hybrid network, 54 common points were identified at a distance of $10,000 \mathrm{~m}, 51$ points at a mutual distance of 5,000 $\mathrm{m}$ and 34 - below 2,000 m, 20 - below $1,000 \mathrm{~m}$, and 5 - below $500 \mathrm{~m}$. Based on the net- 


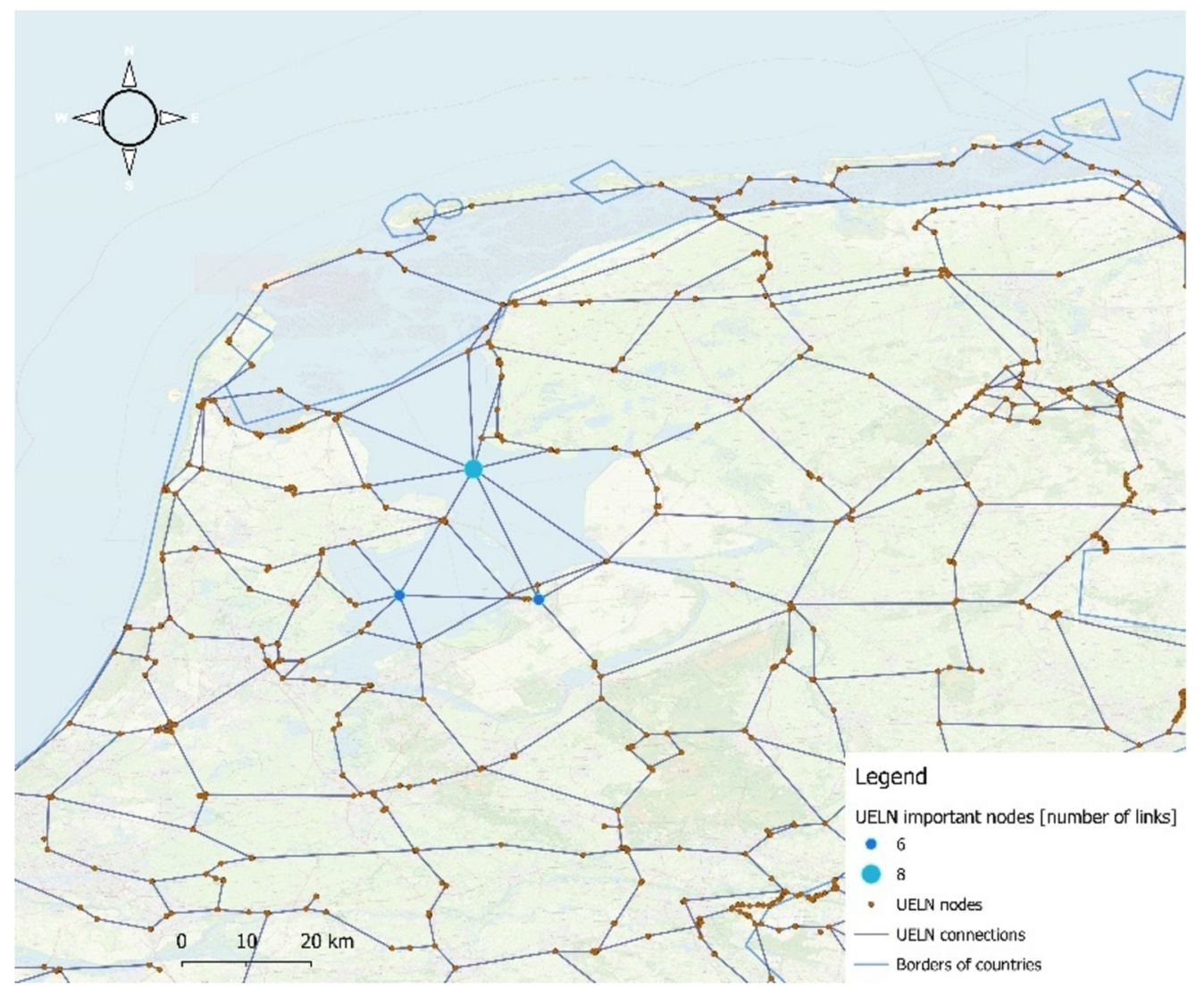

Figure 13: UELN - The United European Levelling Network. The nodes with the highest number of connections. Source: own analysis.

Table 2: Nodes and links in vertical crustal movement network formed from levelling data, GNSS stations data, hybrid network [7].

Number of links Number of nodes levelling data GNSS stations data hybrid network

\begin{tabular}{rrrr}
\hline 1 & & & \\
2 & 29 & 3 & 25 \\
3 & 118 & 20 & 97 \\
4 & 66 & 36 & 59 \\
5 & 21 & 42 & 36 \\
6 & & 14 & 25 \\
7 & 8 & 8 \\
8 & & 1 & 19 \\
9 & & & 12 \\
10 & & & 17 \\
11 & & & 4 \\
12 & & & 2 \\
13 & & & 1 \\
\hline
\end{tabular}

work analysis for the distance of $10,000 \mathrm{~m}$, the number of links was identified using the theory of scale-free networks (Table 2). If there was more than one close nodal point from the levelling, the closest one was taken. An example of a hybrid network is shown in Figure 18.
Distance analysis has shown that the points most significant for the network lie at a max distance of $3,000 \mathrm{~m}$ from one another. Figure 19 presents the distribution of all pseudo-nodal points and pseudo nodal points with the highest number of links.

\subsection{Alignment}

The first alignment of the hybrid network was carried out for preliminary assessment of accuracy. For comparison, alignment of the double levelling network and the network from the GNSS station data was also performed. The same initial parameters were adopted for all variants linked to one adjustment point. During the alignment of the hybrid network, the 50 identified pseudo-nodal points were taken as common points. The results are shown in Figure 20. The smallest errors in relation to the number of observations were obtained for the hybrid network.

The accuracy of selecting the most significant pseudonodal points from among all the identified ones was also assessed. Another levelling (parameters as above) of the 


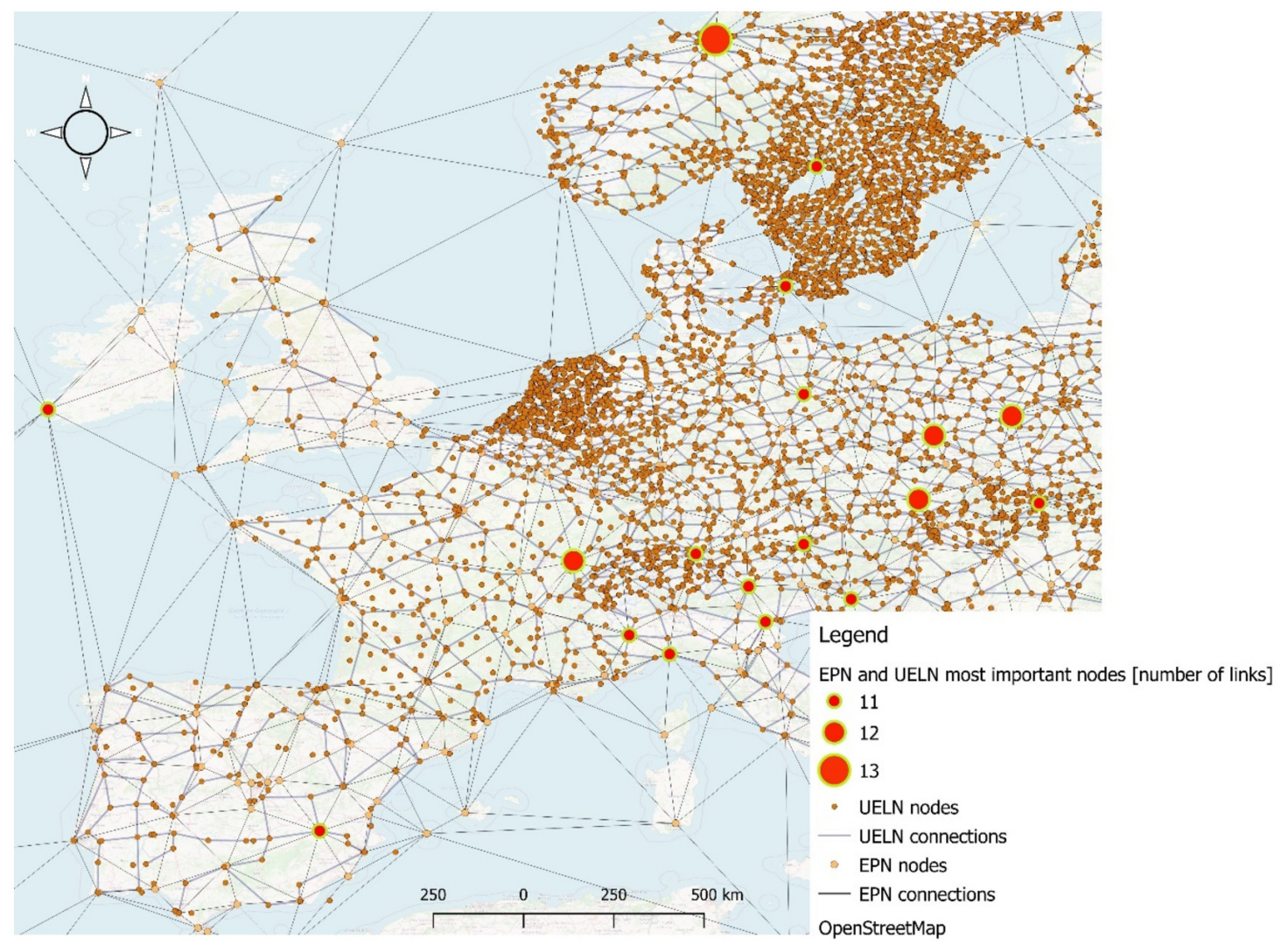

Figure 14: EPN and UELN networks and identification of points with a large number of connections. Source. Own analysis.

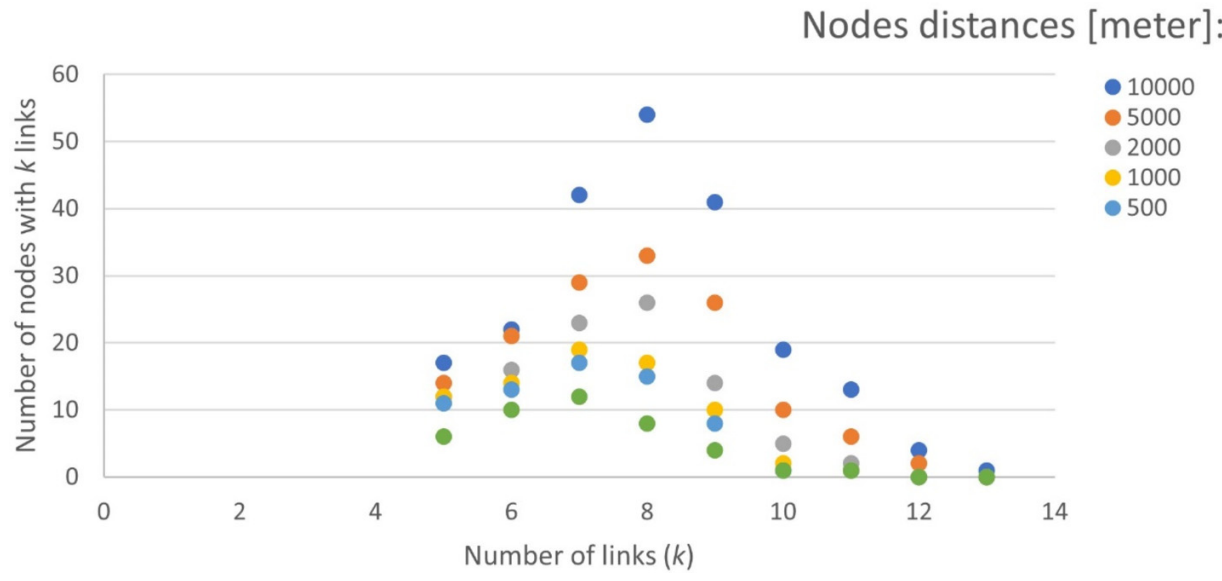

Figure 15: Distribution of the number of links $(K)$ and the number of nodes with $(k)$ links in EPN and UELN network as one structure.

hybrid network was carried out, assuming, from a group of fifty pseudo-nodal points, seven of the most significant points as invariables for levelling and a) varied weights of observations, b) equal weights of observations. The obtained differences in vertical movements of the Earth's crust in the first and second alignment are shown in Figure 21 and Figure 22. The average difference is below
$0.1 \mathrm{~mm} / \mathrm{y}$, with a maximum of $0.15 \mathrm{~mm} / \mathrm{y}$. For weighted observations, the values of vertical movements did not change.

The point errors after alignment in both variants on average ranged from $0.2 \mathrm{~mm} / \mathrm{y}$ to $0.3 \mathrm{~mm} / \mathrm{y}$. It can thus be assumed that the results of the first and second alignment are identical. 


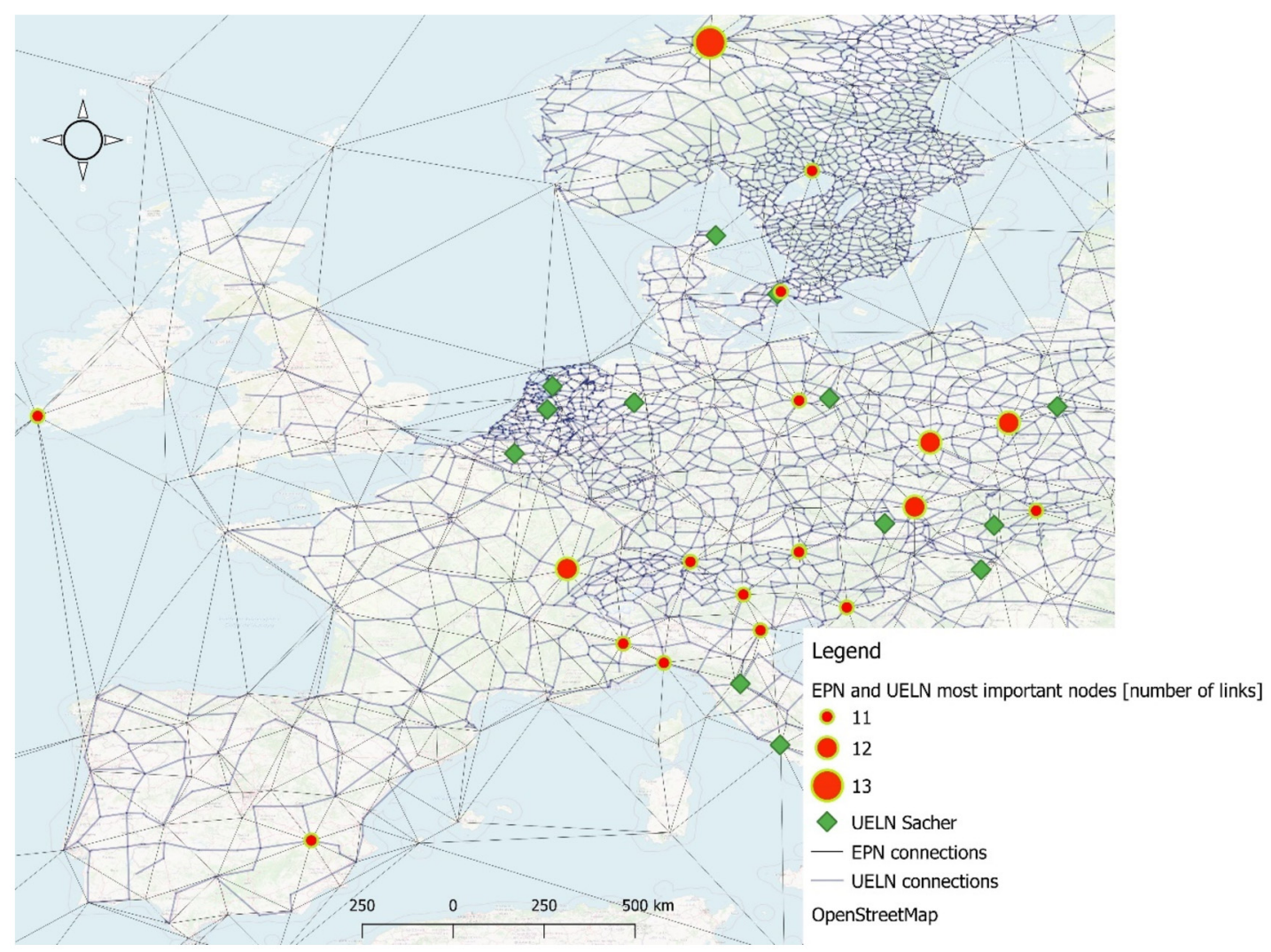

Figure 16: The identified most important nodes in the hybrid network compared with the major points in the UELN network [48]. Source: own analysis.
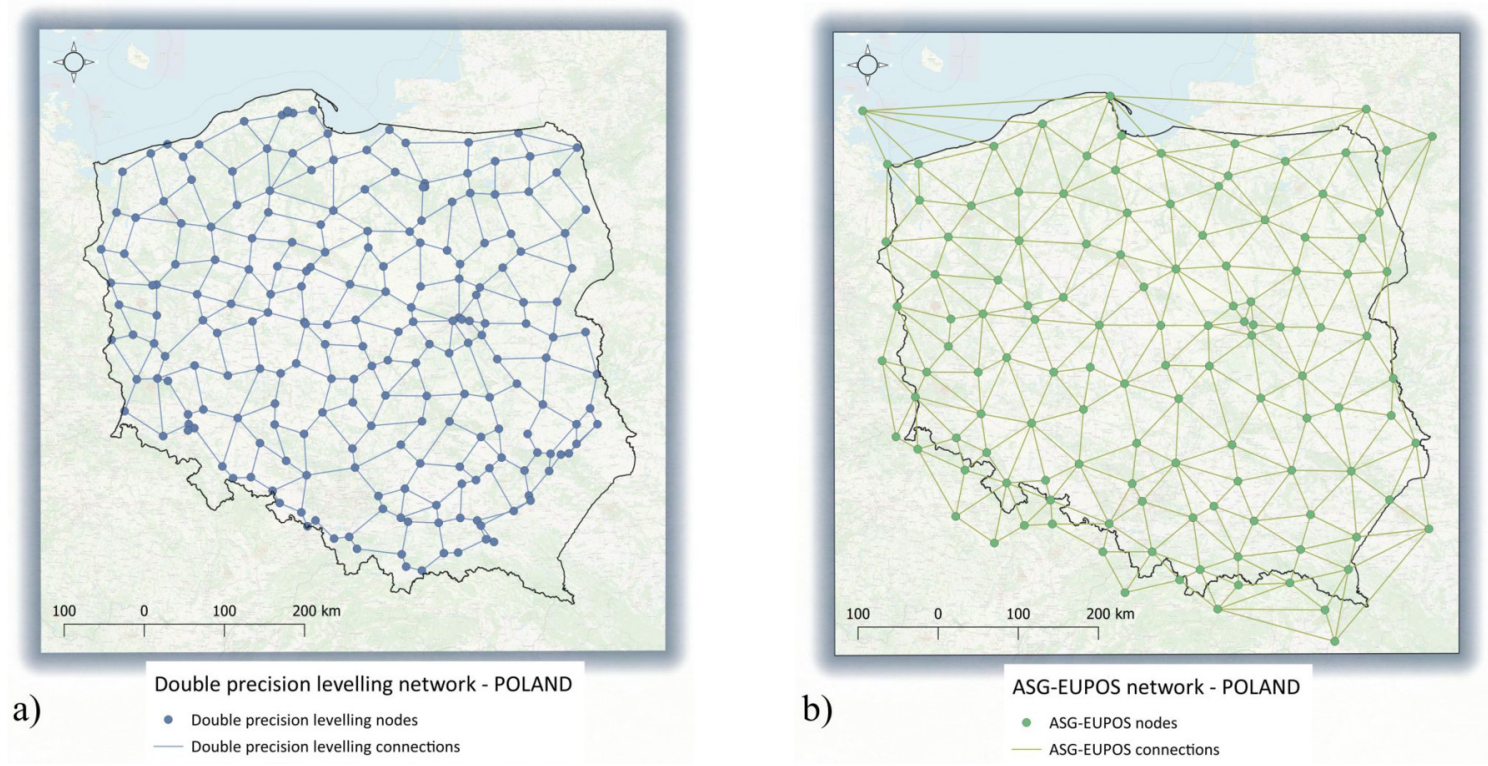

Figure 17: a) double precision levelling network in Poland, b) triangulation between points of the Polish ASG-EUPOS network. 


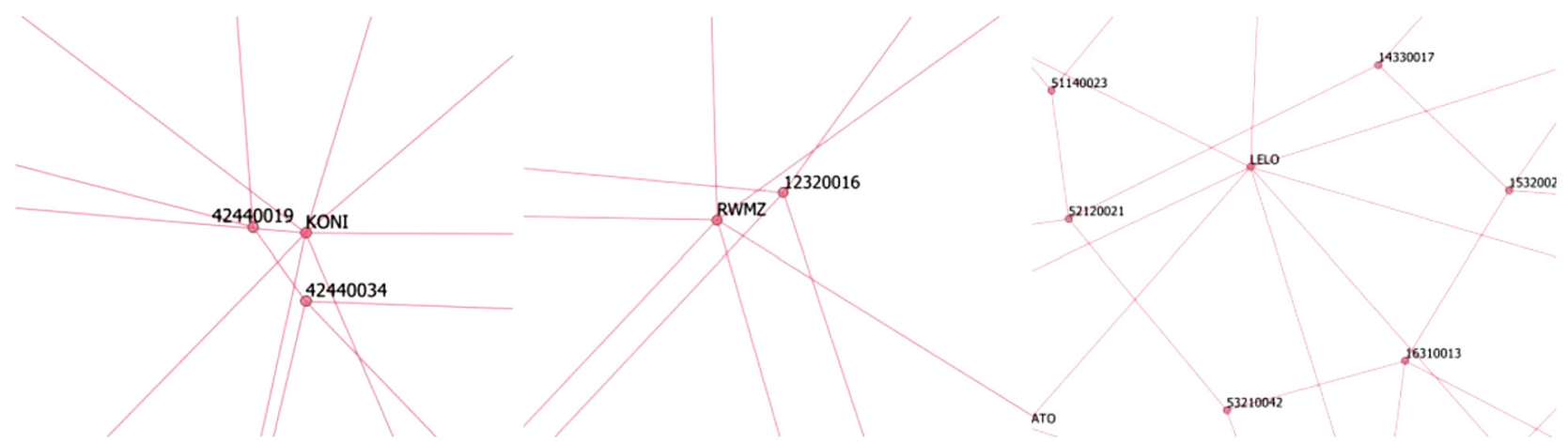

Figure 18: Example of creating a hybrid network a) two double-levelling points and one network from GNSS data, b) one from each network, c) no common points.

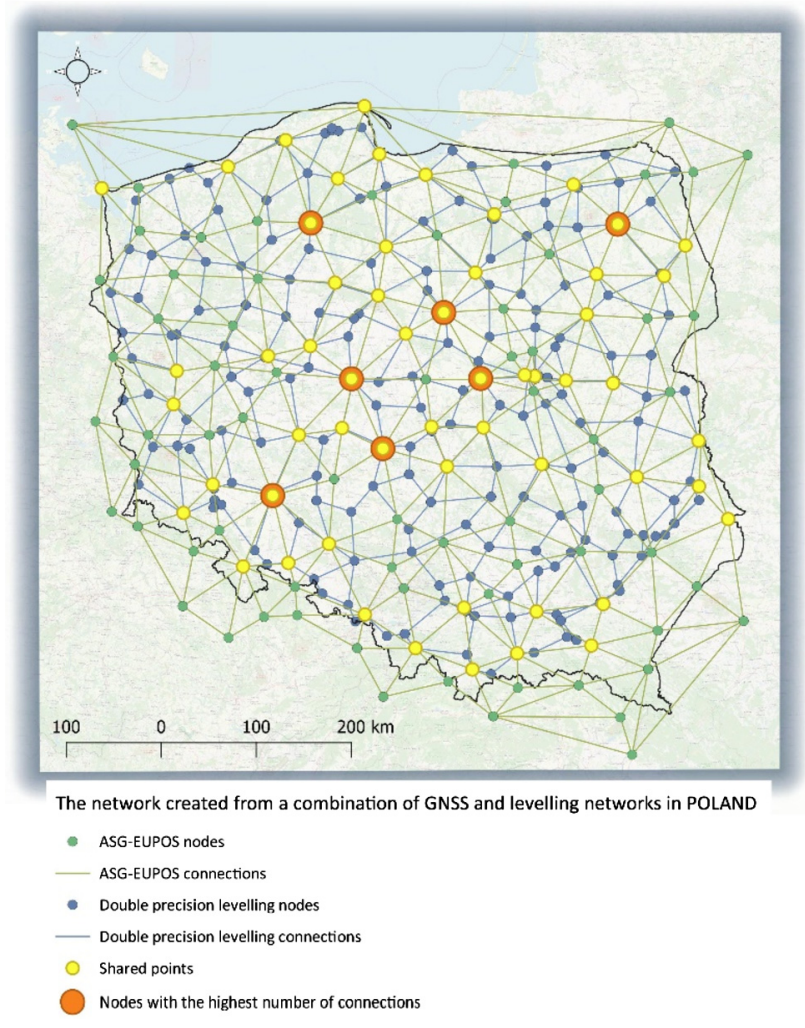

Figure 19: The network created from a combination of GNSS and levelling networks. Squares - shared points, circled squares - nodes with the highest number of connections ("the strongest" nodes).

\section{Discussion and summary}

The variety of geodetic measurement systems provides an opportunity to search for new ways and solutions to combine data sets obtained by different techniques. Many GNSS stations already have their own centres where geometric levelling measurements are performed. However, these measurements are not necessarily cyclical. Measure- ment repeatability is particularly important when assessing surface movements and determining vertical movements of the Earth's crust. Because vertical movements of the Earth's crust are not point-wise, but they affect a certain area, it can be assumed that points lying within a certain distance represent the same movement. Such an assumption allows for the identification of pseudo-nodal points in a (double or triple) levelling network together with stations of the GNSS network (the so-called "pseudonodal points"). In areas less affected by tectonic movements, such an area can have a radius of up to $40 \mathrm{~km} \mathrm{[21].}$ In the current study, this distance was limited to 10 kilometres. An analysis of the identified common points in EULN and EPN has shown that this assumption allows for identifying almost $90 \%$ of the EPN points as pseudo-nodal points, thus confirming its correctness. The denser the distribution of GNNS stations, the lower this criterion should be.

The test adjustment confirmed that the application of the scale-free network theory allows determining the significance of points in a hybrid network. In the hybrid network (UELN + EPN), 18 pseudo-nodal points with the highest number of links were identified. A weak correlation between the main points of the EULN network and the most significant points in the hybrid network was observed. When creating a hybrid network, the nature of the network is also changing from random to scale-free.

The alignment carried out on the example of a hybrid network of vertical movements of the Earth's crust formed from double-levelling data and GNSS station data showed that the pseudo-nodal points with the greatest number of links are important for the network alignment.

This approach allows the relative vertical movements of the Earth's crust in a hybrid network to be determined based on the vertical movements determined at selected GNSS stations, e. g. using PPP technology. These stations, 
GNSS stations data

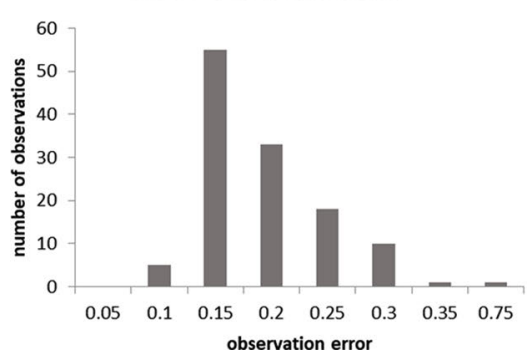

Leveling data

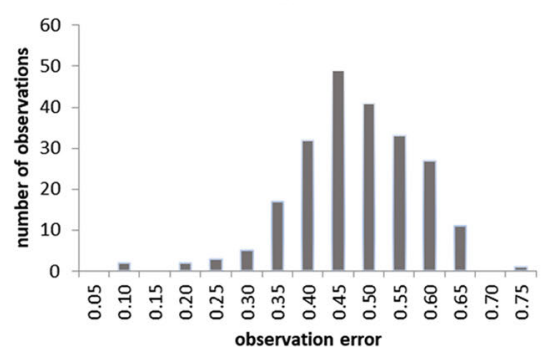

Network

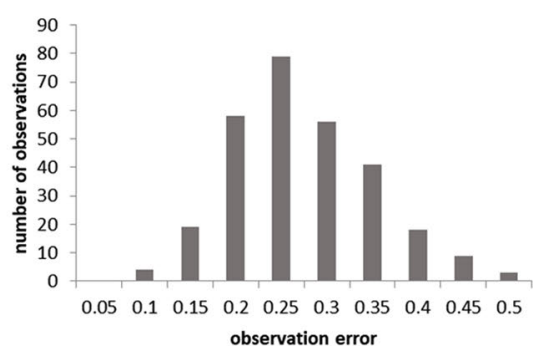

Figure 20: Distribution of errors in determining vertical movements from an alignment of networks a) double levelling, b) GNSS station data, c) hybrid network.

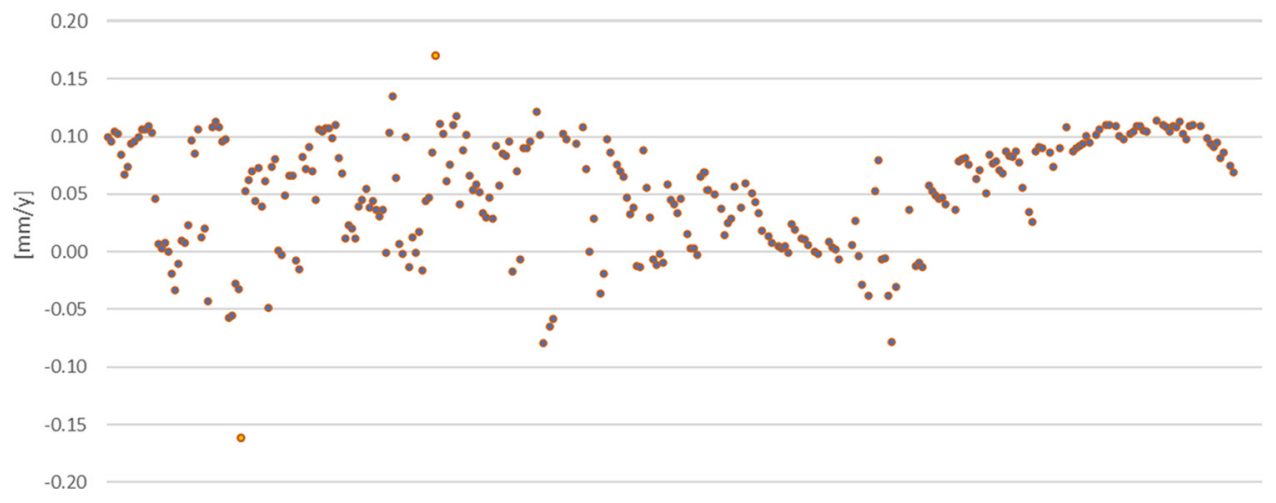

Figure 21: Differences in vertical movements in hybrid network points from the first and second alignment.

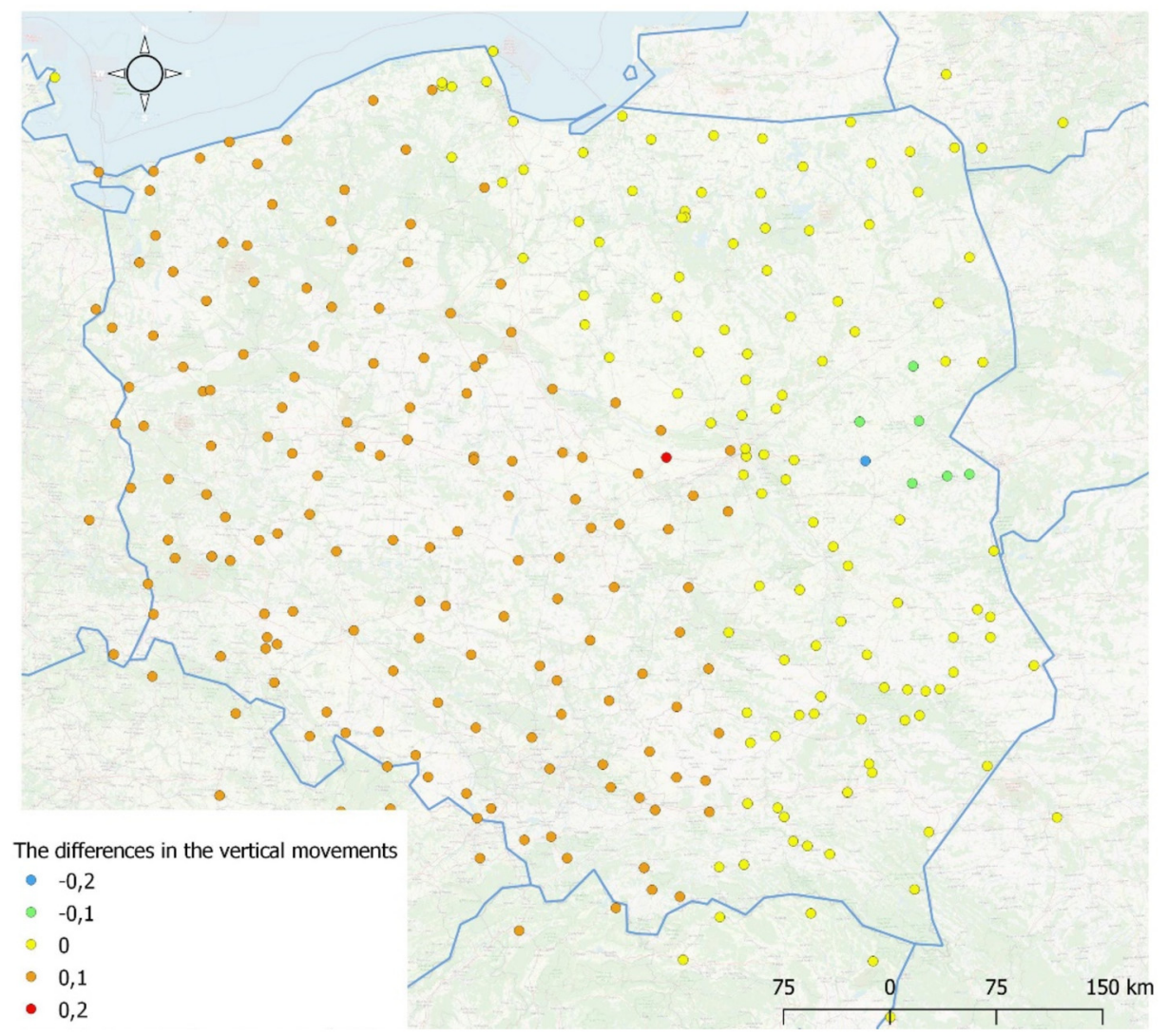

Figure 22: The spatial distribution of the differences in the vertical movements of the earth's crust in Poland. 
in addition to their long operating time and reliable vertical movement determination errors, should also meet the conditions set for the most significant points in a network.

\section{Conclusions}

It is possible to determine the relative vertical movements of the Earth's crust by aligning a hybrid network based on double-levelling data and GNSS station data. Hybrid network alignment requires the identification of common points as pseudo-nodal points. Distance criteria can be used for this identification. The assumed distance criterion of up to $10 \mathrm{~km}$ proved appropriate. The scale-free network theory allows the significance of pseudo-nodal points in a hybrid network to be determined. However, not all pseudo-nodal points in a network are the most significant ones. The alignment of a hybrid network can be based on the pseudo-nodal points most significant for alignment. The analysis of the number of links and significance of points in the network (scale-free network theory) may be an additional criterion for the selection of major points in large geodetic networks such as UELN or EPN.

\section{References}

[1] Abe S, Suzuki N. Scale-free network of earthquakes. EPL Europhys. Lett. 2004, 65, 581.

[2] Appleby G, Rodríguez J, Altamimi Z. Assessment of the accuracy of global geodetic satellite laser ranging observations and estimated impact on ITRF scale: estimation of systematic errors in LAGEOS observations 1993-2014. Journal of Geodesy 2016, 90(12), 1371-1388.

[3] Barabási AL. Linked: The New Science of Networks. Perseus Books Group, New York, NY, USA, 2003.

[4] Barabási AL, Bonabeau E. Scale-free networks. Sci. Am. 2003, 288, 60-69.

[5] Barabási AL, Ravasz E, Vicsek T. Deterministic scale-free networks. Phys. A Stat. Mech. Appl. 2001, 299, 559-564.

[6] Baryla R, Paziewski J. The concept of the GNSS control network densification with precise leveling for ground deformation monitoring. In Environmental Engineering. Proceedings of the International Conference on Environmental Engineering ICEE 2014, Vol. 9, p. 1. Vilnius Gediminas Technical University, Department of Construction Economics \& Property.

[7] Bednarczyk M, Kowalczyk K, Kowalczyk AM. Identification of pseudo-nodal points on the basis of precise leveling campaigns data and GNSS. Acta Geodyn et Geomater. 2018, 15(1), 5-16. doi: 10.13168/AGG.2017.0028.

[8] Brockmann E, Ineichen D, Marti U, Schaer S, Schlatter A, Villiger A. Determination of tectonic movements in the Swiss Alps using GNSS and levelling. In Geodesy for Planet Earth 2012, pp. 689-695.
[9] Bruyninx C, Legrand J, Fabian A, Pottiaux E. GNSS metadata and data validation in the EUREF Permanent Network. GPS Solut. 2019, 23, 106. doi: 10.1007/s10291-019-0880-9.

[10] Choy S, Bisnath S, Rizos C. (2017). Uncovering common misconceptions in GNSS Precise Point Positioning and its future prospect. GPS Solut. 2017, 21(1), 13-22.

[11] Chrzanowski A, Chen YQ, Leal J. (1990). Modelling of ground subsidence from a combination of GPS and levelling surveys. In Global and Regional Geodynamics 1990, pp. 182-191.

[12] Dorogovtsev SN, Mendes JF. Evolution of Networks: From Biological Nets to the Internet and WWW. OUP, Oxford, UK, 2013.

[13] Ekhtari N, Glennie C. High-resolution mapping of near-field deformation with airborne Earth observation data, a comparison study. IEEE Transactions on Geoscience and Remote Sensing 2017, 56(3), 1598-1614.

[14] El-Sheimy N, Valeo C, Habib A. Digital Terrain Modeling: Acquisition, Manipulation, and Applications. Artech House, 2005.

[15] Filmer MS, Featherstone WE, Kuhn M. The effect of EGM2008-based normal, normal-orthometric and Helmert orthometric height systems on the Australian levelling network. Journal of Geodesy 2010, 84(8), 501-513.

[16] Fuhrmann T, Caro Cuenca M, Knöpfler A, et al.Estimation of small surface displacements in the Upper Rhine Graben area from a combined analysis of PS-InSAR, levelling and GNSS data. Geophysical Journal International 2015, 203(1), 614-631.

[17] Guo C, Nie J, Tian J, et al.Vertical ground displacements in the Shandong Province derived from long-term GNSS and leveling surveying. Advances in Space Research 2019, 64(7), 1388-1397.

[18] Hao M, Wang Q, Cui D, Liu L, Zhou L. Present-day crustal vertical motion around the Ordos block constrained by precise leveling and GPS data. Surveys in Geophysics 2016, 37(5), 923-936.

[19] Hausbrandt S. Network adjustment and geodetic calculations. Vol. II. PPWK, Warszawa, 1971 (in Polish).

[20] Hein GW, Leick A, Lambert S. Integrated processing of GPS and gravity data. Journal of Surveying Engineering 1989, 115(1), 15-33.

[21] Heiskanen WA, Moritz H. Physical Geodesy. WH Freeman and Company, San Francisco, CA, 1967.

[22] Hou BJ, Zhong B, Wang WQ. Application of shepard fitting method based on quadric surface in GPS leveling. Engineering of Surveying and Mapping 2007, 1.

[23] Ihde J, Baker T, Bruyninx C, et al.Development of a European combined geodetic network (ECGN). Journal of Geodynamics 2005, 40(4-5), 450-460.

[24] Jagoda M, Rutkowska M, Suchocki C, Katzer J. Determination of the tectonic plates motion parameters based on SLR, DORIS and VLBI stations positions. Journal of Applied Geodesy 2019, 1 (ahead-of-print).

[25] Janicka J. Transformation of coordinates with robust estimation and modified Hausbrandt correction. Zeszyty Naukowe Politechniki Rzeszowskiej. Budownictwo i Inżynieria Środowiska 2012, 59, 1/II, 159-168 (in Polish).

[26] Kadaj R. GPS vector networks with classical observations in terms of modernization of state geodetic networks. Zeszyty. Naukowe. Politechniki Rzeszowskiej, seria Budownictwo i Inżynieria Środowiska, 2007 (in Polish). 
[27] Kenyeres A, Bellet JG, Bruyninx C, et al.Regional integration of long-term national dense GNSS network solutions. GPS Solut. 2019, 23(4), 122.

[28] Klees R, Prutkin I. The combination of GNSS-levelling data and gravimetric (quasi-) geoid heights in the presence of noise. Journal of Geodesy 2010, 84(12), 731-749.

[29] Kocur-Bera K. Scale-free network theory in studying the structure of the road network in Poland. Promet-Traffic Transp. 2014, 26, 235-242.

[30] Kontny B, Bogusz J. Models of vertical movements of the Earth crust surface in the area of Poland derived from leveling and GNSS data. Acta Geodyn et Geomater. 2012, 9(3), 167.

[31] Kostelecký J, Klokocník J, Bucha B, Bezdek A, Förste C. Evaluation of the gravity field model EIGEN-6C4 in comparison with EGM2008 by means of various functions of the gravity potential and by GNSS/levelling. Geoinformatics FCE CTU 2015, 14(1), 7-28.

[32] Kotsakis C, Sideris MG. On the adjustment of combined GPS/levelling/geoid networks. Journal of Geodesy 1999, 73(8), 412-421.

[33] Kowalczyk K, Kuczyńska-Siehień J. Combined adjustment of networks of relative vertical crustal movements from levelling and GNSS data. In EUREF 2017 Symposium, Wroclaw, Poland, May 17-19, 2017.

[34] Kowalczyk K, Rapiński J. Robust network adjustment of vertical movements with GNSS data. Geofizika 2017, 34(1). doi:10.15233/gfz.2017.34.3.

[35] Kowalczyk AM, Bajerowski T. Development of the theory of six value aggregation paths in network modeling for spatial analyses. ISPRS International Journal of Geo-Information 2020, 9(4), 234.

[36] Kowalczyk AM. The analysis of networks space structures as important elements of sustainable space development. In Proceedings of the 10th International Conference “Environmental Engineering”, Vilnius, Lithuania, 27-28 April 2017.

[37] Kowalczyk AM, Kowalczyk K. The network theory in the process of creating and analyzing from vertical crustal movements. In Proceedings of the 14th GeoConference on Informatics, Geoinformatics and Remote Sensing, 2014, pp. 545-552.

[38] Lai Y, Hsu YJ, You RJ. Integrating continuous GPS time series and geodetic leveling data to estimate secular vertical velocity of Taiwan. In AGUFM 2017, G11B-0711.

[39] Lingyun J, Qingliang W, Shuangxu W. Present-day 3D deformation field of Northeast China, observed by GPS and leveling. Geodesy and Geodynamics 2014, 5(3), 34-40.

[40] Mąkolski K, Cacoń S, Košták B, Kapłon J, Kaczałek M. Studies of rock blocks displacements on the upper edge of the "Szczeliniec Wielki" Massif. Acta Geodyn et Geomater. 2005, 2(3), 139.
[41] Massonnet D, Feigl KL. Radar interferometry and its application to changes in the Earth's surface. Rev. Geophys. 1998, 36(4), 441-500.

[42] Newman M, Barabasi AL, Watts DJ. The Structure and Dynamics of Networks. Princeton University Press, Princeton, NJ, USA, 2011.

[43] Nothnagel A, Artz T, Behren, D, Malkin Z. International VLBI service for geodesy and astrometry. Journal of Geodesy 2017, 91(7), 711-721.

[44] Poland M, Bürgmann R, Dzurisin D, et al.Constraints on the mechanism of long-term, steady subsidence at Medicine Lake volcano, northern California, from GPS, leveling, and InSAR. Journal of Volcanology and Geothermal Research 2006, 150(1-3), 55-78.

[45] Poutanen M, Ihde J, Bruyninx C, et al.Future and development of the European Combined Geodetic Network ECGN. In Earth on the Edge: Science for a Sustainable Planet 2014, pp.121-127.

[46] Qin S, Wang W, Song S. Comparative study on vertical deformation based on GPS and leveling data. Geodesy and Geodynamics 2018, 9(2), 115-120.

[47] Sacher M, Liebsch G, Ihde J, Mäkinen J. EVRF07 as realization of the European Vertical Reference System Presented at the Symposium of the IAG Sub-commission for Europe (EUREF) in Brussels, June 18-21, 2008. Submitted to the proceedings.

[48] Sacher M, Liebsch G, Ihde J, Mäkinen J. EVRF2007 as realization of the European Vertical Reference System. In AGUSM, 2009, CG71A-06.

[49] Šimek J, Kostelecki J. Modern geodetic network and datum in Europe. Research Institute of Geodesy, Topography and Cartography, 2000.

[50] Teunissen P, Montenbruck O. (Eds.). Springer Handbook of Global Navigation Satellite Systems. Springer, 2017.

[51] Tregoning P, Rizos C (Eds.). Dynamic Planet: Monitoring and Understanding a Dynamic Planet with Geodetic and Oceanographic Tools, Vol. 130. Springer Science \& Business Media, 2008.

[52] Vestøl O. Determination of postglacial land uplift in Fennoscandia from leveling, tide-gauges and continuous GPS stations using least squares collocation. Journal of Geodesy 2006, 80(5), 248-258.

[53] Zaletnyik P, Volgyesi L, Kirchner I, Paláncz B. Combination of GPS/leveling and the gravimetric geoid by using the thin plate spline interpolation technique via finite element method. Journal of Applied Geodesy 2007, 1(4), 233. 